\title{
Bioactive compounds in potatoes: Accumulation under drought stress conditions
}

\author{
Christina B. Wegener, Gisela Jansen, Hans-Ulrich Jürgens
}

Julius Kuehn Institute, Federal Research Centre for Cultivated Plants, Institute for Resistance Research and Stress Tolerance, Rudolf-Schick-Platz 3, 18190 Sanitz, Germany

Corresponding Author: Christina B. Wegener, Dr, Julius Kuehn Institute (JKI), Federal Research Centre for Cultivated Plants, Institute for Resistance Research and Stress Tolerance, 18190 Sanitz, Germany

Submission date: August 22, 2015; Acceptance date: March 8, 2015, Publication date: March 10, 2015

\begin{abstract}
Background: Potato (Solanum tuberosum) is a valuable source of bioactive compounds. Besides starch, crude fibre, amino acids (AAS), vitamins and minerals, the tubers contain diverse phenolic compounds. These phenolics and AAS confer anti-oxidant protection against reactive oxygen species, tissue damage, and diseases like atherosclerosis, renal failure, diabetes mellitus, and cancer. Climate change and drought stress may become a major risk for crop production worldwide, resulting in reduced access for those who depend on the nutritional value of this staple crop.
\end{abstract}

Objective: The aim of this study is to determine the effect of drought stress on water, lipid soluble antioxidants, anthocyanins (Ac), soluble phenols, proteins, free AAS, peroxidase (POD) and lipid acyl hydrolase activity (LAH) in tuber tissue.

Methods: The study was carried out on three potato genotypes comprising one yellow-fleshed cultivar and two purple breeding clones. The plants were grown in pots (from April to September) in a glasshouse with sufficient water supply and under drought stress conditions. After harvest, the tubers of both variants were analysed for antioxidants measured as ascorbic acid (ACE) and Trolox equivalent (TXE) using a photo-chemiluminescent method. Amounts of anthocyanins (Ac), soluble phenols, proteins, as well as POD and LAH activities were analysed using a UV photometer. Finally, free AAS were measured by HPLC.

Results: The results revealed that drought stress significantly reduces tuber yield, but has no significant effect on antioxidants, Ac, soluble phenols and POD. Drought stress significantly increased the levels of soluble protein $(\mathrm{P}<0.0001)$ and LAH $(\mathrm{P}<0.001)$. Also, total amounts of 
free AAS were higher in the drought stressed tubers $(+34.2 \%$, on average) than in the tubers grown with a sufficient water supply. Above all, proline was elevated due to drought stress.

Key words: anthocyanins, antioxidants, free amino acids, phenols, proteins, tuber quality

\section{INTRODUCTION}

Potatoes (Solanum tuberosum L.) are one of the most important staple crops in cultivation. The tubers are rich in starch, crude fibre, proteins, minerals and vitamins [1]. Potatoes contain various phenolic compounds [2], e.g. $p$-coumaric, caffeic, chlorogenic and ferulic acid as well as anthocyanins [3] which are all secondary metabolites synthesized via phenylpropanoid metabolism [4]. Also the potato protein has a good biological value and nutritive quality [5]. Environmental stress induces antioxidant protein [6], which may be impacted by climate change. Plants can adapt to such stressful conditions by synthesizing a set of protective proteins as reported for potato [7], chickpea [8], different Vitex species [9] and rice [10]. Also, Late Embryogenesis Abundant (LEA) proteins were found to be involved in protecting plants, cell membranes and other proteins from drought stress [11, 12, 13, 14]. However, such stress responses alter biochemistry and nutritional quality. Therefore, the aim of this study was to ascertain effect of drought stress on antioxidants in potato tubers measured as ascorbic acid (ACE) and Trolox equivalent (TXE), anthocyanins (Ac), soluble phenols, proteins, free amino acids (AAS), peroxidase (POD) and lipid acyl hydrolase enzyme activities (LAH).

\section{METHODS}

Plant Material: One yellow-fleshed cultivar (cv.) Agave and two purple breeding clones St 89403 and St 3792 were involved in the experiments carried out in two consecutive years (2010/11). The plants were grown in pots filled with a turf (95\%)-sand mixture (5\%) from April to September in a greenhouse. The mean temperature $\left({ }^{\circ} \mathrm{C}\right)$ during the growing seasons of the first and second year was as followed: May, 9.7/12.8; June, 15.1/16.1; July 20.6/17.9; August, 17.1/17.1; September, 12.8/14.7. The standard recommended rates for commercial pesticides and fertilizer were applied throughout the growing seasons of both experimental years. Hakaphos ${ }^{\mathrm{R}}$ Red (8+12+24+4; COMPO, Germany) was utilized as a NPK fertilizer supplemented with magnesium $(\mathrm{MgO})$ and trace elements $\mathrm{B}, \mathrm{Cu}, \mathrm{Fe}, \mathrm{Mn}, \mathrm{Mo}$ and $\mathrm{Zn}$. After harvest, the tuber yield was determined for each genotype and variant, and the tubers were stored at $5{ }^{\circ} \mathrm{C}$ until analysis.

Drought Stress: The drought stress was applied as detailed by Wegener et al. [15]. Control plants were grown with sufficient water supply (watered daily). Drought stressed plants were watered daily for seven weeks after planting. Following tuber initiation, the water supply was fully stopped for six days. After the drought period, each plant received only $50 \mathrm{ml}$ of water per day, an amount that was further reduced to $30 \mathrm{ml}$ daily per plant, from the middle of August until the end of experiments. The summer of the second test year was colder and darker. Hence, a second drought period of six days was inserted 11 weeks after planting in that year. Each experimental set for the control and the drought stress variant of each genotype was carried out with four replicates, comprising four plants per genotype and replication. The plants were grown in a randomized experimental design. 
Analyses: Lyophilized tissue samples were used for the analyses of anthocyanins according to Fuleci and Francis [16] and for the assay of LAH activity according to Bohac [5], both with modifications [17]. Total amounts of Ac were measured at $545 \mathrm{~nm}$ on a UV spectrometer (Kontron Instruments, Germany), then calculated as malvidin-3-p-coumaryl-glucoside and expressed as milligrams per 100 grams freeze-dried matter (FDM). The LAH activities were assayed at $410 \mathrm{~nm}$ on a UV photometer and one enzyme unit was defined as the increase in 0.1 absorbance units per minute and milligram FDM. The POD activity was assayed in tissue extracts at $470 \mathrm{~nm}$ on a UV photometer according to Bi et al. [18] with modifications [15]. One POD enzyme unit was defined as the increase in 0.1 absorbance units per minute and microliter of the tissue extract. Antioxidants present in the tissue extracts were measured by means of a photo-chemiluminescent method detailed by Popov \& Lewin [19] on a Photochem instrument (AnalyticJena AG, Germany), using an ACW kit for water soluble antioxidants and an ACL kit for lipid soluble antioxidants according to the manufacturer's recommendations (AnalytikJenaAG). Antioxidants were expressed in microgram equivalents of the appropriate reference compound, i.e. as ascorbic acid (ACE) and Trolox equivalent (TXE) per milligram of fresh weight $(\mathrm{FW})$, respectively. Soluble phenols were measured in the tissue extracts using Folin-Ciocalteu reagent (Sigma-Aldrich, Germany) as described [20]. The assays were performed at $725 \mathrm{~nm}$ on a UV photometer and the amounts of phenols (coumaric acid equivalent) were expressed in grams per kilogram of tuber FW. Soluble proteins were determined in the tissue extracts by means of a Bradford assay using Roti ${ }^{\mathrm{R}}$-Quant reagent (Roth, Germany) and bovine serum albumin (Sigma-Aldrich, Germany) as a standard. The absorbance was measured at $595 \mathrm{~nm}$ on a UV spectrophotometer. Amounts of proteins were expressed as $\mathrm{mg} / \mathrm{mL}$ of tissue extract. Total amounts of free AAS were measured by the method of Cohen \& Michaud [21] adapted to a Luna C18 (2) bonded silica column (Phenomenex, Germany) according to Hernández-Orte et al. [22] with modifications [17]. The HPLC assay was carried out on an Agilent 1100 series liquid chromatograph system (Agilent Technologies, Germany), and amounts of AAS were expressed in milligrams per $100 \mathrm{~g}$ of $\mathrm{FW}$.

All analyses mentioned above were performed at least in triplicate. The analyses started in November and were finished in December of each year. For the preparation of lyophilized tissue powder and extract samples used in the analyses ten medium sized tubers were taken from each genotype and replica as an average sample.

Statistics: The data were subjected to a generalized linear model for the analysis of variance, using the SAS 9.2 statistical package (PROC GLM, Tukey-test, SAS Institute Inc., Cary, NC, USA) and $\mathrm{P} \leq 0.05$ was regarded to be statistically significant.

\section{RESULTS AND DISCUSSION}

Yield: The tuber yield of all three genotypes was significantly $(\mathrm{P} \leq 0.05$, all $)$ reduced by drought stress in both years, i.e. on average by $44 \%$ in the first year and by $34 \%$ in the second year [15]. This strong yield reduction indicates that the drought stress was successfully applied thus enabling the study of its impact on the bioactive compounds in tuber tissue. Moreover, it should be pointed out that the free amino acid proline as a stress-related marker was enhanced in drought stressed tubers of all genotypes [17]. 
Anthocyanins: Ac pigments, belonging to the widely distributed flavonoid group, are bioactive plant polyphenols with known salutary effects [23]. They are involved in response to various environmental stresses such as excessive light, UV-B radiation, drought, and pathogen attack. Moreover, these compounds possess antioxidant capacity [24]. Their radical scavenging capacity was reported to be many times higher than that of vitamins E and C [25]. Antioxidant activity is considered as one of the major function of anthocyanins [24]. Hence, it was important that in both years the purple clones exhibited relatively high amounts of Ac in their control and droughtstressed tubers, whereas no color pigments were found in tissue of the yellow-fleshed cv. Agave [15]. The differences in Ac between the two purple clones were statistically not significant. Their Ac contents ranged on average from 235 (Year 1) to $362 \mathrm{mg} 100 \mathrm{~g}^{-1}$ (Year 2) for the control tubers grown with sufficient water supply and from 206 (Year 1) to $359 \mathrm{mg} 100 \mathrm{~g}^{-1}$ (Year 2) for drought-stressed tubers. The levels of color pigments were on average higher in the second year than in the first year with its relatively warm summer. As reported, the differences between the two years were statistically significant $(\mathrm{P} \leq 0.01)$ [15]. The cooler temperature during the main growing period of the second year fostered the accumulation of Ac pigments. Moreover, it was important that the differences in Ac between the control and the drought stress variants of purple clones were statistically insignificant [15]. It seems therefore, that drought stress has no evident effect on the amount of Ac pigments in tuber tissue.

Peroxidases: The results revealed significant genotypic differences in POD enzyme activities [15]. The latter ranged on average from 0.29 (Year 2) to $0.43 \mathrm{U}^{-1} \mathrm{l}^{-1}$ (Year 1) for the control tubers and from 0.29 (Year 2) to $0.57 \mathrm{ULl}^{-1}$ (Year 1) for the drought stressed tubers of the three genotypes involved in this study. The POD levels were significantly $(\mathrm{P} \leq 0.05)$ higher in the first year than in the second year, a tendency that was contrary to that observed for anthocyanins. However, the differences in POD between the control and the drought stress variants were statistically not significant [15]. It seems thus, that drought stress has no evident effect on POD, as noticed already for Ac. It is assumed that the peroxidase enzymes compliment anthocyanins in the plant antioxidant system [24]. The data indicating that both POD and Ac react similarly under drought stress conditions was consistent with their overlapping function.

Antioxidants: The three genotypes varied considerably in their concentrations of antioxidants measured as ascorbic acid (ACE) and Trolox equivalent (TXE) (Table 1). In both types of antioxidants, the purple clones exceeded the yellow fleshed cv. Agave. Thus, St 89403 had several times higher antioxidant activities than the latter. Moreover, the observations revealed that the ACE and TXE values were higher on average in the first year than in the second year (Table 1), a tendency coinciding with POD values that were also higher in the first test year. In fact, the differences in antioxidants between the years were all statistically significant $(\mathrm{P} \leq 0.05)$. But, in this frame it is interesting to note that all together the differences in ACE and TXE between the control and the drought stressed variants were statistically not significant (Table 1). It seems thus, that the effect of drought stress on both types of antioxidants is less prominent, as noticed similarly with Ac and POD. 
Table 1. Contents of antioxidants measured as ascorbic acid (ACE) and Trolox equivalent (TXE) in control and drought stressed tubers (Mean $\pm \mathrm{SD}$ ).

\begin{tabular}{|c|c|c|c|c|}
\hline \multirow[t]{2}{*}{ Genotypes } & \multicolumn{2}{|l|}{$\mathrm{ACE}\left(\mu \mathrm{g} \mathrm{mg}^{-1}\right)$} & \multicolumn{2}{|l|}{ TXE $\left(\mu \mathrm{g} \mathrm{mg}^{-1}\right)$} \\
\hline & Control & Drought & Control & Drought \\
\hline \multicolumn{5}{|l|}{ 1. Year } \\
\hline St 89403 & $2.36 \pm 0.36 \mathrm{a}^{\dagger}$ & $2.08 \pm 0.09 \mathrm{a}^{\dagger}$ & $4.33 \pm 0.25 \mathrm{a}^{\dagger}$ & $4.46 \pm 0.48 \mathrm{a}^{\dagger}$ \\
\hline St 3792 & $1.14 \pm 0.12 \mathrm{~b}^{\dagger}$ & $1.32 \pm 0.24 b$ & $3.67 \pm 0.38 b^{\dagger}$ & $4.30 \pm 0.28 \mathrm{a}^{\dagger *}$ \\
\hline Agave & $0.38 \pm 0.07 \mathrm{c}^{\dagger}$ & $0.21 \pm 0.05 \mathrm{c}^{*}$ & $0.34 \pm 0.02 \mathrm{c}^{\dagger}$ & $0.28 \pm 0.03 b$ \\
\hline Average & $1.29 \pm 0.88^{\dagger}$ & $1.20 \pm 0.81^{\dagger}$ & $2.78 \pm 1.84^{\dagger}$ & $3.01 \pm 2.04^{\dagger}$ \\
\hline \multicolumn{5}{|l|}{ 2. Year } \\
\hline St 89403 & $1.76 \pm 0.11 \mathrm{a}^{\dagger}$ & $1.61 \pm 0.17 \mathrm{a}^{\dagger}$ & $2.92 \pm 0.28 \mathrm{a}^{\dagger}$ & $2.81 \pm 0.21 \mathrm{a}^{\dagger}$ \\
\hline St 3792 & $0.94 \pm 0.07 \mathrm{~b}^{\dagger}$ & $0.98 \pm 0.15 b$ & $2.50 \pm 0.18 \mathrm{a}^{\dagger}$ & $2.97 \pm 0.53 \mathrm{a}^{\dagger}$ \\
\hline Agave & $0.25 \pm 0.04 c^{\dagger}$ & $0.24 \pm 0.02 c$ & $0.27 \pm 0.03 b^{\dagger}$ & $0.26 \pm 0.03 b$ \\
\hline Average & $0.99 \pm 0.65^{\dagger}$ & $0.94 \pm 0.60^{\dagger}$ & $1.90 \pm 1.22^{\dagger}$ & $2.01 \pm 1.33^{\dagger}$ \\
\hline
\end{tabular}

a,b,c Genotype means followed by different letters in the same column differ significantly at $\mathrm{P} \leq 0.05$. Differences between the years are significant at ${ }^{\dagger} \mathrm{P} \leq 0.05$. Differences between the control and drought stress variants are significant at the level ${ }^{*} \mathrm{P} \leq 0.05$.

Soluble Phenols: Several phenols, i.e. non-flavonoids mainly derived from cinnamic acid, are also part of the plant antioxidant system. Most common hydroxycinnamates are $p$-coumaric, caffeic, ferulic as well as 5-O-caffeoylquinic acid (referred to as chlorogenic acid) [24]. As the results have shown, there were significant differences in soluble phenols between the genotypes (Table 2). In both years, the purple clones exhibited the highest levels. The differences in the phenol content between the two years were statistically significant $(\mathrm{P} \leq 0.05)$ in the control variant only. However, it is important to note that the differences in this respect between the control and the drought stressed variants were statistically not significant (Table 2). This may show that the effect of drought stress on soluble phenols is less evident, as noticed for Ac, POD, ACE and TXE (Table 1).

It seems that the level of antioxidants comprising phenols, Ac and POD was high enough to respond successfully to drought, which is a condition associated with oxidative stress. The finding that these components are unaffected by drought stress might be considered a crop advantage of tubers, especially regarding antioxidants and their protective effects [26]. Besides Ac and POD, also the phenols may have contributed to the overall antioxidant potential measured in tuber tissue (Table 1).

Soluble Proteins: Potatoes are one of the most important protein sources in the world [27], and the amino acid profile may be superior to cereals and legumes [28]. Importantly, the three genotypes tested differed in concentrations of soluble protein (Table 2), and St 89403 revealed the highest level. Only within the control variant were the differences in protein statistically significant between the years (Table 2). In addition, it should be noted that in all three genotypes the amount of soluble protein was significantly increased due to drought stress (Table 2). This 
overall trend may demonstrate that drought stress, which had no evident effect on Ac, POD, ACE, TXE and soluble phenols, has a clear effect on protein expressed in tuber tissue. Accordingly, the latter might play an important role within the whole network of stress and/or adaptive responses in tuber tissue.

With regard to the nutritional value of tubers, this enhancement can be seen as an advantage, because plant protein is an important source for amino acids in human nutrition. About 20-40\% of soluble protein in potato tubers comprises patatin, a plant glycoprotein exhibiting lipid acyl hydrolase (LAH) activities [29]. Lipid acyl hydrolases are lipolytic enzymes associated with changes of membrane lipids and the release of fatty acids [30]. In fact, the LAH was significantly $(\mathrm{P} \leq 0.05)$ enhanced in drought-stressed tubers, compared to control tubers grown with sufficient water supply [17]. Thus, the LAH levels were elevated on average by $77.1 \%$ (Year 1) and $87.6 \%$ (Year 2) due to drought stress, a tendency which may support the findings obtained in the context with soluble protein.

Table 2. Contents of soluble phenols and protein in control and drought stressed tubers (Mean \pm $\mathrm{SD})$.

\begin{tabular}{|c|c|c|c|c|}
\hline \multirow[t]{2}{*}{ Genotypes } & \multicolumn{2}{|c|}{ Soluble phenols $\left(\mathrm{g} \mathrm{kg}^{-1}\right)$} & \multicolumn{2}{|c|}{ Soluble protein $\left(\mathrm{mg} \mathrm{ml}^{-1}\right)$} \\
\hline & Control & Drought & Control & Drought \\
\hline \multicolumn{5}{|l|}{ 1. Year } \\
\hline St 89403 & $2.93 \pm 0.18 a$ & $2.92 \pm 0.25 a$ & $7.60 \pm 1.37 \mathrm{a}^{\dagger}$ & $12.64 \pm 1.22 \mathrm{a}^{* * *}$ \\
\hline St 3792 & $1.77 \pm 0.11 b^{\dagger}$ & $2.00 \pm 0.27 b$ & $4.54 \pm 0.50 b$ & $4.58 \pm 0.08 \mathrm{c}$ \\
\hline Agave & $0.62 \pm 0.08 c$ & $0.65 \pm 0.04 c$ & $3.46 \pm 0.14 \mathrm{c}^{\dagger}$ & $7.68 \pm 0.30 b^{\dagger * *}$ \\
\hline Average & $1.77 \pm 1.00^{\dagger}$ & $1.86 \pm 0.99$ & $5.20 \pm 1.99^{\dagger}$ & $8.30 \pm 3.53^{* * *}$ \\
\hline \multicolumn{5}{|l|}{ 2. Year } \\
\hline St 89403 & $3.12 \pm 0.21 \mathrm{a}$ & $2.62 \pm 0.14 \mathrm{a}^{*}$ & $8.05 \pm 0.10 \mathrm{a}^{\dagger}$ & $10.95 \pm 0.48 \mathrm{a}^{* *}$ \\
\hline St 3792 & $2.26 \pm 0.04 b^{\dagger}$ & $1.97 \pm 0.10 b^{*}$ & $4.83 \pm 0.13 b$ & $6.00 \pm 0.28 \mathrm{c}^{* *}$ \\
\hline Agave & $0.62 \pm 0.02 c$ & $0.64 \pm 0.05 c$ & $4.15 \pm 0.33 \mathrm{c}^{\dagger}$ & $6.45 \pm 0.19 b^{\dagger^{* *}}$ \\
\hline Average & $2.00 \pm 1.09^{\dagger}$ & $1.74 \pm 0.87$ & $5.68 \pm 1.79^{\dagger}$ & $7.80 \pm 2.35^{* * *}$ \\
\hline
\end{tabular}

a,b,c Genotype means followed by different letters in the same column differ significantly at $\mathrm{P} \leq 0.05$. Differences between the years are significant at ${ }^{\dagger} \mathrm{P} \leq 0.01$. Differences between the control and drought stress variants are significant at ${ }^{*} \mathrm{P} \leq 0.05,{ }^{* *} \mathrm{P} \leq 0.01$ and ${ }^{* * *} \mathrm{P} \leq 0.0001$.

Free Amino Acids: About $49 \%$ of total amino acids in tuber tissue are non-proteinogenic, free amino acids [26]. Total free AAS was elevated in drought-stressed tubers of all genotypes (+34.2\%, on average) [17]. A further experiment on these three genotypes (Wegener \& Jürgens, unpublished data) underlined this tendency and confirmed that differences in total AAS between

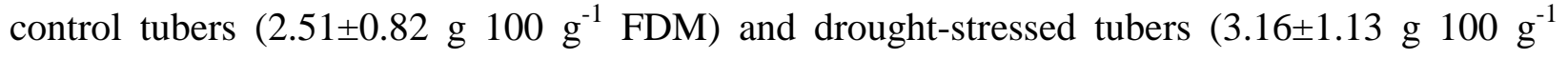
FDM $)$ are statistically significant $(\mathrm{P}<0.001)$. Besides proline as a stress-related signal, 
asparagine was especially increased under drought stress conditions. These results were not surprising, since AAS function as osmolytes that can stabilize proteins and other macromolecules under stress conditions [31]. In addition, the observed increase in total amounts of free AAS due to drought may confer a nutritional advantage.

In summary, these results indicate that free amino acids, together with soluble protein such as lipid acyl hydrolases are associated with the drought stress responses of tubers. Moreover, anthocyanins, peroxidases, soluble phenols, water (ACE) and lipid soluble antioxidants (TXE) seem to be minimally affected. It should be pointed out however, that the drought stress applied in this study represents only one of many scenarios that plant may experience in nature. Hence, it needs to be established if the findings presented here can be transferred to other scenarios and to other potato genotypes when grown under drought stress conditions. Further studies will focus on starch accumulated under conditions of drought stress, because the potato starch is seen as a risk factor of type 2 diabetes [32].

Conclusions: These data have clearly shown that drought stress has no significant effect on anthocyanins, peroxidases, soluble phenols, water (ACE) and lipid soluble antioxidants (TXE) accumulated in potato tuber tissue. But, it is important to note that drought stress significantly increased the contents of soluble protein, lipid acyl hydrolase activities and total concentration of free amino acids. Increased amino acid content increases the nutritional value of potatoes. Also of note, the purple clones (above all St 89403) ranked on the highest levels in ACE, TXE, phenols and proteins.

Abbreviations: amino acids (AAS), anthocyanins (Ac), ascorbic acid equivalent (ACE), cultivar (cv.), freeze-dried matter (FDM), high performance liquid chromatography (HPLC), lipid acyl hydrolase (LAH), peroxidase (POD), Trolox equivalent (TXE)

Competing interest: The authors have no financial interest or conflicts of interest.

Author's contributions: All author contributed to this work.

\section{REFERENCES:}

1. Buckenhüskes HJ: Nutritionally relevant aspects of potatoes and potato constituents. In AJ Haverkort, PC Struik, Eds; Potato in Progress; Academic Publishers: Wageningen, 2005:17-26.

2. Friedman M: Chemistry, biochemistry, and dietary role of potato phenols: A review. J Agr Food Chem 1997, 45:1523-1540.

3. Brown CR: Antioxidants in potato. Am J Potato Res 2005, 82:163-172.

4. Crozier A, Jaganath IB, Clifford MN: Phenols, polyphenols and tannins: An overview. In A Crozier, MN Clifford, H Ashihara, Eds; Plant Secondary Metabolites; Blackwall Publishing Ltd: Oxford, 2006, 1-24.

5. Bohac RJ: A modified method to purify patatin from potato tubers. J Agr Food Chem 1991, 39: 1411-1415. 
6. Liu YW, Han CH, Lee MH, Hsu FL, Hou WC: Patatin, the tuber storage protein in potato (Solanum tuberosum L.) exhibits antioxidant activity in vitro. J Agr Food Chem 2001, 51:4389-4393.

7. Vayda ME, Schaeffer HJ: Hypoxic stress inhibits the appearance of wound response proteins in potato tubers. Plant Physiol 1988, 88:805-809.

8. Mafakheri A, Siosemardeh A, Bahramnejad B, Struik PC, Sorabi Y: Effect of drought stress and subsequent recovery on protein, carbohydrate contents, catalase and peroxidase activities in three chickpea (Cicer arietinum) cultivars. Aust J Crop Sci 2011, 5:1255-1260.

9. John DBA, Kumar PBJR, Gracelin DHS, Jency SS: Drought stress and its impact on protein in three species of Vitex. J Stress Physiol Bichem 2011, 3:152-158.

10. Ali GM, Komatsu S: Proteomic analysis of rice leaf sheath during drought stress. J Proteome Res 2006, 5: 396-403.

11. GalauGA, Wang HYC, Hughes DW: Cotton Lea5 and Leal4 encode atypical late embryogenesis-abundant proteins. Plant Physiol 1993, 101:695-896.

12. Hong-Bo S, Zong-Suo L, Ming-An S: LEA proteins in higher plants: Structure function, gene expression and regulation. Colloid Surface B 2005, 45:131-135.

13. Goyal K, Walton LJ, Tunnacliffe A: LEA proteins prevent protein aggregation due to water stress. Biochem J 2005, 388:151-157.

14. Hand SC, Menze MA, Toner M, Boswell L, Moore D: LEA proteins during water stress not just for plants anymore. Ann Rev Physiol, 73:115-134.

15. Wegener CB, Jansen G: Antioxidants in different potato genotypes: Effect of drought and wounding stress. Agriculture 2013, 3:131-146.

16. Fuleki T, Francis FJ: Quantitative methods for anthocyanins. 1. Extraction and determination of total anthocyanins in cranberries. J Food Sci 1968, 33:72-77.

17. Wegener CB, Jansen G, Jürgens HU: Influence of drought and wounding stress on soluble phenols and proteins in potato tubers. Sust Agric Res 2014, 3:1-15.

18. Bi JL, Felton GW, Murphy JB, Howles PA, Dixon RA, Lamb CJ: Do plant phenolics confer resistance to specialist and generalist insect herbivores? J Agric Food Chem 1997, 45:4500-4504.

19. Popov IN, Lewin G: Photochemiluminescent detection of antiradical activity: IV. Testing of lipid soluble antioxidants. J Biochem Bioph Meth 1996, 31:1-8.

20. Cahill MD, McComb JA: A comparison of changes in phenylalanine ammonia-lyase activity, lignin and phenolic synthesis in the roots of Eucalyptus calophylla (field resistant) and E. marginata (susceptible) when infected with Phytophthora cinamomi. Phys Mol Plant Pathol 1992, 40:315-332.

21. Cohen SA, Michaud DP: Synthesis of a fluorescent derivatizing reagent, 6aminoquinolyl-N-hydroxysuccinimidyl carbamate, and its application for the analysis of hydrolysate amino acids via high-performance liquid chromatography. Anal Biochem 1993, 211:279-287

22. Hernandez-Orte P, Ibarz MJ, Cacho J, Ferreira V: Amino acid determination in grape juices and wines by HPLC using a modification of the 6-aminoquinolyl-Nhydroxysuccinimidyl carbamate (AQC) method. Chromatographia 2003, 58:29-35. 
23. Hooper L, Cassidy A: A review of the health care potential of bioactive compounds. J Sci Food Agric 2005, 86:1805-1813.

24. Hatier HB, Gould HS: Anthocyanin Function in Vegetative Organs. In K Gould, K Davies, C Winefield, Eds; Anthocyanins: Biosynthesis, Functions and Applications. Springer Science + Business Media LLC, New York, 2009:1-19.

25. Wang H, Cao G, Prior RL: Oxygen radical absorbing capacity of anthocyanins. J Agric Food Chem 1997, 45:304-309.

26. Young IS, Woodside JV: Antioxidants in health and disease. J Clin Pathol 2001, 54:176186.

27. De Romana GL, Maclean WC, Placko RP, Graham GG: Fasting and postprandial plasma-free amino acids of infants and children consuming exclusively potato protein. $\mathrm{J}$ Nutr 1981, 111:1766-1771.

28. Millward DJ: The nutritional value of plant based diets in relation to human amino acids and protein requirements. P Nutr Soc 1999, 58: 249-260.

29. Andrews DL, Beames B, Summers MD, Park WD: Characterization of lipid acyl hydrolase activity of the major potato (Solanum tuberosum L) tuber protein, patatin, by cloning and abundant expression in a baculovirus vector. Biochem J 1988, 252:199-206.

30. Galliard T: The enzymic deacylation of phospholipids and galactolipids in plants. Biochem J 1971, 121:379-390.

31. Yancey P: Water stress, osmolytes and proteins. Am Zool 2001, 41:699-709.

32. Halton TL, Willett WC, Liu S, Manson JE, Stampfer MJ, Hu FB: Potato and french fry consumption and risk of type 2 diabetes in women. Am J Clin Nutr 2006, 83: 284-290 